\title{
Conceptual Fluency in Second Language Teaching: An Overview of Problems, Issues, Research Findings, and Pedagogy
}

\author{
Marcel Danesi \\ University of Toronto \\ BC 21., 73 Queen's Park Crescent, Toronto ON, M5S 1K7 \\ E-mail: marcel.danesi@utoronto.ca
}

Received: 17-06-2015

Accepted: 28-09-2015

Published: 01-01-2016
Advance Access Published: October 2015

doi:10.7575/aiac.ijalel.v.5n.1p.145
URL: http://dx.doi.org/10.7575/aiac.ijalel.v.5n.1p.145

\begin{abstract}
Conceptual Fluency (CF) and the related notion of metaphorical competence (MC) emerged in the mid-1980s as a pedagogical response to the research findings and insights that were crystallizing in the fledgling field at the time of cognitive linguistics, and specifically, of conceptual metaphor theory. Since then, a considerable amount of work has been conducted on these notions investigating their main premises, researching their efficacy as teaching-learning tools, and exploring their pedagogical implications. Over three decades later, this paper presents an overview of the relevant work and raises the questions and issues that these notions continue to raise.
\end{abstract}

Keywords: conceptual fluency, second language learning, conceptual metaphor, metaphorical competence, mental calquing, interference, second language pedagogy

\section{Introduction}

Research on the critical role that figurative language plays in culture and cognition started mushrooming in the cognitive sciences in the late 1970s (Pollio, Barlow, Fine, \& Pollio, 1977, Ortony, 1979, Honeck \& Hoffman, 1980, Lakoff \& Johnson, 1980). Cumulatively, it led to a reassessment of literalist-based theories of semantics and of the role of syntax in the processing of language. The work showed, essentially, that figurative expressions in discourse were hardly exceptional or idiomatic; they were systematic and thus revelatory of the conceptual-semantic system guiding linguistic choices in ordinary forms of communication.

The implications of this line of inquiry for second language acquisition (SLA) theories were instantly obvious. Danesi (1986), for example, argued that the control of figurative language, which he called metaphorical competence (MC), was crucial if true second language (L2) proficiency were to be achieved by classroom learners. The idea of MC in SLA overlapped somewhat with that of communicative competence, but it seemed initially to have a broader scope. Danesi $(1992,1995)$ went on to formulate the notion of conceptual fluency (CF) as the ability to use the conceptual-semantic system that produced figurative discourse systematically. CF was based on the assumption that figurative discourse, being systematic, was as teachable as anything else in the L2. Starting in the mid-1990s, this assumption was put to the test in various studies and investigations. Since then, the number of studies has increased considerably. The purpose of this paper is to revisit $\mathrm{CF}$ and MC in light of the relevant studies, discussions, and critiques, in order to better assess their viability as useful constructs. There areas particular interest to the present review include the validity of MC and $\mathrm{CF}$, how to identify metaphorical content and, as a corollary, conceptual errors, and the actual teachability of MC.

\section{Conceptual Fluency}

A recurrent type of classroom error that cannot be pigeonholed simply as lexical interference from the L1, or as the result of a knowledge gap in the use of L2 idiomatic language, can be seen in an utterance such as Io sono caldo ("I am hot") that a beginning student of Italian might utter in response to the question Come va? ("How's it going?"). The student's intended meaning refers to his or her response to the weather conditions, but the actual meaning of the utterance to a native speaker of Italian would be "I am (sexually) aroused" or "I have a fever." What seems to be at play in such utterances is a form of "mental calquing," a phenomenon noted early on in contact studies and in SLA research (Weinreich, 1953, Lado, 1957, 1964). This is a process whereby L2 learners put together the words and phrases of the target language into sentences whose meanings reflect L1 conceptual-figurative structure. Simply put, students tend to "think" in English (their L1) as they "speak" Italian (L2). This guides their choice of words and other structures in the formation of sentences and utterances.

The students' utterances lack the "conceptual fluency" (CF) that would turn them into utterances with the intended meaning. In other words, they lack the kind of competence that inheres in assigning the required concepts to the choice and organization of words and phrases into L2 sentences. This type of competence goes beyond communicative competence in the traditional sense of that term. It has been called metaphorical competence (MC), because a large part 
of this competence involves the ability to glean figurative meaning from words in utterances. These notions have various analogies to the Notional-Functional Syllabus of the 1970s (Van Ek, 1975, Wilkins, 1976), which was devised just before the relevant work on figurative language in the cognitive sciences. Especially critical in all this line of inquiry is the role of conceptual metaphors in SLA, as subsequent research on MC or its versions has shown (Low, 1988, Lindstromberg, 1991, Bowers, 1992, Johnson \& Rosano, 1993, Irujo, 1986, 1993, MacLennan, 1994). Conceptual metaphors, as is well known, are the associative concepts that underlie specific sets and subsets of linguistic (actual) metaphorical utterances (Lakoff \& Johnson, 1980). So, for example, "He's a tiger," "Your friend is a pussycat," and "The professor is a hawk," are all specific examples (linguistic metaphors) of the conceptual metaphor, people are animals or something similar). Without going into details here, suffice it to say that research has been showing how diffuse conceptual metaphors are in all forms of human expression. As Littlemore (2001a, p. 461) has pointed out, incorporating the notion of conceptual metaphor in SLA has very broad implications, since it entails imparting to L2 learners "the ability to think up one's own unconventional metaphors."

One of the earliest attempts to incorporate rhetorical-metaphorical content into the structure of the teaching syllabus was the Contrastive Rhetoric Movement, which took root in the mid-1960s before both conceptual metaphor theory and the derived pedagogical notions of MC and CF (Kaplan, 1966, 1978). The key idea of this movement was that a large portion of negative transfer from the L1 occurs at a rhetorical level rather than at a literalist level, which will "violate the expectations of the native reader" (Kaplan, 1966, p. 4). The movement did not spread widely, not because of lack of interest, but because it did not have the empirical support it required that came in the late 1970s from research on figurative language, although in its updated versions it continues to attract many language educators (Piper, 1985, Leki, 1991, Connor, 1996, Grabe \& Kaplan, 1996, Matsuda 1997).

Teaching students literal concepts before venturing into rhetorical and idiomatic domains has traditionally constituted the core of L2 pedagogy. But this mode of presentation of input does not block the students' use of mental calquing (as mentioned above) to construct L2 utterances is an instinctive tendency that shows up constantly in student interlanguages. The proposal of CF theory is to counteract this tendency by incorporating the notion of MC into L2 pedagogy. Chapetón (2010), for instance, found that, if encouraged and instructed to use metaphor systematically in the L2, students came up with fairly good approximations of novel metaphors that a native speaker might create.

The teachability of MC has come under some critical scrutiny. Valeva (1996) and Kecskes (1999), for example, questioned whether MC could be taught directly in a classroom setting. Valeva argued that literal concepts cannot be ignored in the early stages of pedagogy. While her critique is certainly well founded, it ignores the reality of mental calquing that manifests itself from the beginning and if not taken into account may lead to a fossilized discourse style that lacks CF. Danesi (2003) pointed out that the literalist aspect of pedagogical input can be taken into account, by positing three levels of calquing:

Isomorphism: "He goes to school"

Partial overlapping: "He enjoys school"

Differentiation: "He played hooky from school"

Isomorphisms are instances when the L1 and L2 reflect the same conceptual structures and thus produce the same type of syntax and semantics; for this reason they require no adjustment by the learner. The sentence "He goes to school" is isomorphic both structurally and conceptually in Italian: Lui va a scuola. If we designate the conceptual systems as C1 (the native system) and $\mathrm{C} 2$ (the target system), it can be said that cases of isomorphism will not produce conceptual interferences because the $\mathrm{C} 1$ and the $\mathrm{C} 2$ overlap completely, generating the same grammatical and semantic structure. But classroom experience shows that isomorphisms are happenstance occurrences, rather than systematic (frequent) ones.

Partial overlapping involves instances of lexical phraseology and syntax that are slightly different in the two languages. So, for example, "He is enjoying school" needs to be adjusted in Italian to "He is having fun at school": Lui si diverte a scuola. Here the adjustment is minimal, but necessary, otherwise the student will produce an awkward L2 utterance. One can, of course, argue that this is a matter of grasping syntactic structure. While this is largely correct, it still constitutes an area where adjustment, not replacement, is required. Moreover, syntactic phenomena such as the use of prepositions are connected to the conceptual systems in contact, not independent from them as the research mentioned above has largely verified.

Finally, an utterance such as "He played hooky from school" needs a full adjustment because it involves two differentiated conceptual systems. In Italian, the appropriate expression is Lui marina la scuola. While this may seem to be a simple idiomatic replacement, the fact remains that such a replacement requires the ability to understand that two different conceptual systems are at work, which students typically assume not to be the case and thus will calque the English phrase onto the Italian one, word-for-word, even if this often includes a code switch, *Lui gioca "hooky" dalla scuola. The inability to make conceptual adjustments at this level is a constant pattern in student interlanguages and in their processing of new input. The relevant research seems to bear this out. Xia Li-yun (2007) conducted two types of tests on Chinese learners of English - a discourse-completion test and a dialogue-interpretation test - finding that the learners were influenced by their $\mathrm{C} 1$, so that they produced anomalous utterances similar to the one here in Italian. Philip (2010) found that C1 knowledge interferes constantly with the acquisition of $\mathrm{C} 2$, highlighting the importance of MC in overall proficiency (see Boers, 2011 for an overview of research findings in this area). 


\section{Problems and Issues}

The general research on conceptual metaphors on SLA, lends support to the notions of CF and MC both directly and indirectly, in the sense that it either alludes to the notions explicitly or is based on similar notions. An underlying question in all this is: How does one identify input that will need to undergo conceptual adjustment; that is, how can the teacher identify the metaphorical content of utterances that they wish to impart to students systematically? Chapetón (2010) examined this issue as well, showing how to flesh out instances of linguistic metaphor in contextualized corpus data that belonged to specific overarching concepts. Moreover, she discovered that students have little difficulty assigning metaphorical status to L2 utterances when instructed specifically to do so. Indeed, she found that the students tended to "hyper-metaphorize," as Littlemore (2001a, 2001b) also found in his work- that is, without systematic instruction in MC, learners tend to create metaphorical expressions in the L2 that are awkward or else border on incomprehensibility.

In a recent study, Nacey (2013) compared texts written by Norwegian learners of English to those written by British students, aiming to see if the L2 students produced more metaphors (hyper-metaphors) than L1 novice writers. Nacey found, actually, that novel metaphors are rare in both native and non-native speakers, unlike previous research findings. However, a closer look at Nacey's data shows that "novel metaphor" is loosely defined and the writing tasks were highly structured, thus limiting the range of conceptual creativity required to carry them out.

Lantolf (1999) argued that even at a surface level, there is no question about the validity of the MC construct, but that the issue was how to identify metaphorical content (differentiated conceptual systems) from other kinds of content (for example, isomorphisms) that require special pedagogical intervention. Kecskes \& Papp (2000a, 2000b) suggested, as well, that this was a crucial topic because otherwise learner utterances would carry mainly $\mathrm{C} 1$ structures calqued upon L2 phraseology. Boers (1999, 2000a, 2000b, 2001, 2004, 2011, Boers \& Demecheler, 2001, Boers \& Lindstromberg, 2006) proposed a less ambitious goal, suggesting that it was more reasonable to instill a "metaphor awareness" in learners, rather than the ability to generate metaphors in the L2, so that they will at least be able to "organize the steady stream of figurative language they are exposed to" (Boers, 2000a, p. 564), which, as Littlemore (2002, p. 484), argues, will give learners "the ability to interpret metaphors quickly in conversation." Similar arguments, along with the kinds of queries indicated above, appear in a host of studies (Kövecses \& Szabó, 1996, Lazar, 1996, Russo, 1997, Deignan \& Solska, 1997, Cooper, 1999, Kecskes, 1999, Cameron \& Low, 1999, 2000, Bortfeld, 2002, Charteris-Black, 2002, Cameron, 2003, Grant \& Bauer, 2004, Velasco, 2005, Lantolf \& Thorne, 2006, Hashemian \& Nehzad, 2007).

Identifying metaphorical content in order to include it in input phases of pedagogy involves the employment and didactic adaptation of conceptual metaphor theory. The main technique is that of image schema, which allows us to classify seemingly disparate conceptual content together. For example, the conceptually incorrect utterance above, Io sono caldo, should be Io ho caldo (literally "I have heat") reflecting the presence of the container schema, as Lakoff \& Johnson call it $(1980,1999)$. Now, the relevant point is that this is not an isolated example of the use of a schema, but rather part of a regular utilization. The same schema undergirds a whole series of expressions in Italian, such as Io ho torto, tu hai ragione, loro hanno sonno, and so on, which are translated as "I am wrong," "you are right," "they are sleepy." So, concepts such as heat, cold, sleep, and the like are perceived as substances within a container-if the container is the human body, then it (literally) has (contains) it, hence the use of avere. This allows us to explain verb choices in Italian that seem to be idiomatic as, instead, as regular. The underlying mechanism in all is the container schema. Similar approaches can be found in a growing body of literature (e.g., Achard \& Niemeier, 2004, Cameron \& Low, 1999, Hinkel, 2006, Holme, 2004, 2009, Littlemore, 2009). So, fundamentally, the idea is to organize the syllabus in image-schematic ways that reflect grammatical patterns which, in turn, can be taught in the context of the conceptual schemas.

The problem of metaphor identification was confronted head-on. Essentially, the issue of extracting metaphor in naturally-occurring data is a problematic one, but not impossible to realize. Using image schema theory as a template, studies have shown that a syllabus can be set up that follows a series of themes expressed in target domains with the source domains becoming the concrete means of realizing those domains, linguistically and conceptually. Several procedures for linguistic metaphor identification have been proposed by metaphor researchers in response to their type of corpus, their research objectives and questions. Stefanowitsch (2006) suggests three strategies for extracting expressions that may manifest conceptual structure from non-annotated corpora:

1. selecting source domains (WAR, ANIMALS, COLORS, and so on) and then liking these to lexical fields to which these are connected in actual discourse texts;

2. selecting target domains (EMOTIONS, ECONOMICS, PERCEPTION, and so on) that are representative of specific types of speech acts or conversational themes;

3. searching texts in a random fashion and then organizing the metaphorical schemas into pedagogical vehicles.

Problems have emerged with all three, but they are not, in our view, intractable. The main one is that it is difficult to come up with the themes required for a specific teaching unit. The Notional-Functional Syllabus mainly gave suggestions based on an analysis of common conversations in typical interactive situations, and it would seem that the same of approach can be used to design a conceptual syllabus. Work on identification and various metaphor awareness studies, such as those by Boer indicated above, present a rather complex picture. This is totally expected though, 
because language cannot be reduced to a series of categories to be put together like a Lego set. It requires the interaction of several levels, of which MC is a central one.

The research has, in fact, shown how multivariate metaphor is. Andrews (2014, p. 110) points out that metaphor is systematic, but it is also deliberate or emergent. So, it is part of semantics, but also part of pragmatics. Another problem is the incidence and role of metonymy and irony in discourse and how this can be used to cultivate CF. These are still ongoing problems, as far as we can tell. Solving them will resolve the longest standing dilemma of SLT-how to impart native-like control over language as a meaning-using and meaning-making system.

The other main problem that has emerged in the relevant literature is the connection of MC of communicative and sociopragmatic competence. In other words, how does the student gain the ability to use figurative language strategically in interactions, in writing, and in other functional ways? Without belaboring the point, this is a generic question for all SLT models, even those that stress the sociopragmatic aspects. Research in SLA is diversifying its approach to the acquisitional parameters involved in the various kinds of competencies that are involved in learning a second language in classroom environments.

\section{Teachability}

The question of where to locate the notion of $\mathrm{MC}$ in a syllabus and how to treat it pedagogically raises more questions. Some of these have been tackled insightfully by Andreou \& Galantomos (2008, 2009), who suggest that MC can be included as part of communicative competence pedagogy, so that its various discursive functions can then be connected to grammatical and lexical cues. Identifying $\mathrm{MC}$ as separate from, though connected to, communicative competence has, at the very least, didactic value. The problem is how to teach non-literal concepts, which emerge when words are organized into phrases and sentences. How does one teach students to use the concept of "love" appropriately when discussing it in the L2, given that its conceptual nature produces a plethora of metaphorical forms (to fall in love, to become crazy over love, and so on)? It is precisely in attempting to answer this kind of pedagogical question that the notion of MC presents itself as a potentially useful framework, because it suggests that many abstract concepts can be taught directly, as Andreou \& Galantomos $(2008,2009)$ have persuasively argued and illustrated.

To address the teachability issue, Danesi (2008) conducted a study at Middlebury College in Vermont during the summer of 2001. An experimental and a control group of comparable intermediate class learners of Italian as an L2 (24 learners in total) took the same course in different classrooms. The experimental group was trained using insights from relevant work on MC, such as the ones by Kecskes (2000a, 2000b), Andreou \& Galantomos (2008), by a group of volunteers. They created the reaching units using notions such as image schemas, source domain searching, and so on, in tandem with the relevant communicative functions and linguistic structures that the students were expected to learn in the course. The instructors in a comparable control group taught the class without any direct incorporation of MC. Essentially, students in the experimental group were taught about relevant source domains (image schemata) for various topics in the common syllabus and then they were provided with materials to practice them explicitly. Some of the exercises included applying their metaphorical knowledge to novel pragmatic tasks in order to see if the students could apply it in unscripted ways. Corrections to the exercises of the experimental group were explained in class and various aspects of grammar and vocabulary were tied to these explanations.

The two groups were then given a series of eight writing tasks at the end of term: "Write a brief paragraph describing an event that made you angry in Italian;" "Write a brief paragraph describing your first experience of love;" and so on. The student texts were then analyzed in terms of: (1) how many appropriate figurative phrases were used; and (2) how many conceptual interferences surfaced. The most salient finding was that the MC group did indeed use metaphorical language much more than the control group, as expected. Ratings of the appropriateness of the language in the texts were given by native speakers of Italian (two professors of the language who were on the campus as visiting professors).

Of the 164 metaphors overall used by the experimental group, 135 were judged as appropriate by the two native speakers, for an $82.31 \%$ accuracy rating; of the 25 times that the control group used a metaphorical term, only 4 were judged as appropriate by the native speakers, for a $16 \%$ accuracy rating. The significance level using the t-test is at the $p$ $<.01$. When examined by the research team, it was found, moreover, that in all cases of inappropriateness, the source was $\mathrm{C} 1$ interference. For example, one student in the control group wrote: Anch'io sono sempre verde di gelosia (literally: "I too am also green with envy always"), showing the use of verde with an English metaphorical meaning.

The results showed two relevant things: First, the conceptually-trained group used metaphorical concepts freely and rather appropriately, vis-à-vis the control group which showed a lower control of MC. Second, the experimental group showed a remarkable ability to apply conceptual metaphors to novel writing tasks, whereas the control group did not. The study thus showed that MC can be taught directly, even if in a casual complementary fashion, and that, when it is not, the tendency of students is either to avoid metaphorical expressions altogether or to apply $\mathrm{C} 1$ meanings to phrases.

A similar pattern of findings crystallizes from the relevant literature (e.g., Tyler \& Evans, 2004, Beréndi, Csábi, \& Kóvecses, 2008, Skoufaki, 2008, Tyler, 2008, Boers \& Lindstromberg, 2009). Li (2009), for instance, found that only by direct pedagogical intervention could the MC of Chinese learners of English be maximized so that their utterances would be conceptually fluent. Hashemian (2013) carried out an experiment to explore the efficacy of instructions on how to use conceptual metaphors with Iranian intermediate learners of English. Sixty participants were assigned to two experimental groups and a control group. One of the two experimental groups was exposed to the explicit teaching of metaphors via the use of 20 reading passages annotated for their conceptual content. The other experimental group was 
taught metaphorical forms of writing through implicit instruction. The control group was given classroom instruction without any focus on MC. All three groups took the same pretest and posttest. Using ANOVA and the analysis of covariance, Hashemian found that the group taught to use MC explicitly achieved higher results on the posttest, indicating a positive correlation between teaching and the development of $\mathrm{MC}$.

Despite such positive findings, some problems persist. Charteris-Black (2002), for instance, found that the simple teaching of metaphorical knowledge does not necessarily lead to the production of acceptable linguistic forms in functional tasks. There is a gap to be bridged between learning the conceptual schemata and learning how they are realized linguistically. Aware of this shortcoming, Shirazi \& Talebinezhad (2013) tackled the problem with a group of Iranian learners of English. The learners were simply exposed to L2 metaphorical utterances systematically and routinely, rather than exceptionally (as idioms). At the end of the instruction period they found statistical significance in the learners' use of metaphor in a native-like fashion.

In a review of the research findings published between 1996 and 2010, Boers (2011) suggested that they showed, cumulatively, that pedagogical strategies incorporating MC into the syllabus did produce an increase in conceptual fluency. As Boers (2011: 227) puts it: "It must also be recognized that Cognitive Semantic ventures into language pedagogy stand a lot to gain from a closer collaboration with mainstream applied linguistics, not only with regard to general insights into the nature of second language acquisition but also with regard to this type of research methodology."

An extensive research study by Norafkan (2013) investigated the effect of exposure to authentic and computer-based English language materials on learners' MC and CF in Iranian L2 classrooms. She started by assuming that classroombased L2 learning using standard course books would allow for various degrees of linguistic and communicative competence to develop, but that this approach would not lead to conceptual fluency. Nebraskan divided 53 Persian learners of English in Iran into experimental and control groups. Standard textbook materials were used with the control group while authentic MC-based materials and instruction by trained native speakers as online teachers were employed with the experimental class. Qualitative and quantitative data were collected based on questionnaires as well as pre-, post- and delayed post-tests. Both groups improved in their English language proficiency, but the results of the study at the post-test stage showed that the conceptually-trained L2 learners' written and oral texts showed a significantly higher level of conceptual skill when compared to the control group's texts. Participants in the experimental group produced less marked discourse with a higher metaphorical density. Overall, the study showed that CF and MC are two related phenomena and that the development of one influences the other.

In a similar type of study, Hashemian \& Nehzad (2007) gathered a group of 139 subjects majoring in English as an L2, subdividing them into three groups. Before the study, their MC was assessed by a teacher-made pre-test. Then, the two researchers trained the experimental group with a CF-oriented syllabus. Post-tests designed to determine any relation between $\mathrm{CF}$ and $\mathrm{MC}$ were given, and the scores were compared with the total scores of other tests and procedures. The results corroborated again showed that by systematically taking L2 conceptual metaphors and their linguistic realizations into account and incorporating them into the input to which students are exposed, students not only developed the ability to understand C2-dense English texts, but also to produce such discourse effectively.

\section{Conceptual Errors}

The notions of MC and CF have had implications for error theory. In an extensive study of errors, Russo (1997) came to the conclusion that $\mathrm{C} 1$ transfer produces the type of errors that are most disruptive of comprehensibility of student output. These "conceptual errors" are traced to the fact that students unconsciously use their C1 to program parts of their utterances and this, as mentioned, involves mental calquing. Gradually, and with greater mastery of the L2, the students gain higher and higher levels of conceptual fluency. But as the research has shown this will occur more directly if they have been taught to access the $\mathrm{C} 2$ directly.

It is, of course, possible that even during the earliest stages learners will produce native-like utterances, even though they are relying on the $\mathrm{C} 1$. The reason for this is the level of isomorphism between the $\mathrm{C} 1$ and $\mathrm{C} 2$, discussed above, which triggers positive conceptual transfer. Clearly, the degree of isomorphism between the two will vary, depending on the particular languages and cultures in question. It is safe to assume, however, that there will be some degree of isomorphism. It is at the level of conceptual differentiation (above) where negative conceptual transfer occurs.

As Danesi \& Grieve (2010) found, the most disruptive errors in meaning-transfer during communication are negative conceptual transfers. While errors of phonology can interfere with comprehensibility, the student's intended meaning can still be reconstructed somewhat successfully; but if the error is conceptual then this becomes ever more problematic - a finding emerging also in intercultural communication contexts where the same language (English) is used by nonnative speakers in regular interactions (Danesi \& Rocci 2009). There are several implications deriving from this type of consideration. Mahmoodzadeh (2014), for example, argues that a conceptually-based contrastive analysis, based on the notion of MC, can provide a better understanding of how conceptual errors can reveal stages of learning in student interlanguages and thus suggest ways of intervening systematically in order to produce a higher degree of CF. An example of this could be in the area of prepositional uses. In Italian, the English phrase "I read it in the newspaper" is rendered with L'ho letto sul giornale. The contrast between English in and Italian su ("on") is due to C1 and C2 in contrast. In English the schema producing the preposition in is the container one. Information is in a newspaper, because it is conceptualized as a container. In Italian, on the other hand, the newspaper is conceptualized as a surface on which the information lies. This contrast in conceptual systems is the source of common student errors such as * $L$ ' $h o$ 
letto nel giornale. Teaching prepositions within this kind of framework is actually a straightforward task that produces significant results in blocking such errors, as Boers \& Demecheleer argued as far back as 1998. Similar perspectives on the pedagogy of prepositions can be found in Lindstromberg $(1996,1998)$.

\section{Conclusion}

As a consideration of the relevant research above suggests, the question of the validity and the teachability of MC is largely an uncontroversial one. It can, seemingly, be taught as systematically as any other aspect of the L2, and it can be linked to linguistic and communicative competencies through syllabus design. There are, nonetheless, problems and issues hat still need resolution. It is relevant to note that teaching manuals are now being produced that include MC in them, at least implicitly (Radden \& Dirven, 2007, Lindstromberg, 2010). Studies by Littlemore \& Low (2006a) and Kecskes $(1999,2000)$ have also shown that CF plays a considerable role in guiding learners to successfully formulating highly conventionalized units of discourse whose occurrence is sensitive to standardized communicative situations "Hi, how's it going?" "Not bad, and you?", and so on. Danesi (2000) found that CF relies on a type of mental navigation of metaphorical and non-metaphorical circuits in the network of concepts that inhere in even a simple sentence. He thus defines CF more specifically as the ability to navigate source domains in the L2 during discourse programming. The L2 learner can rarely be a participant in real discourse situations until she or he has acquired the ability to do exactly this. Already in 1993, Irujo suggested that students should be taught strategies to deal with figurative language, since those strategies would help them take advantage of the semantic transparency of some idioms. Kövecses \& Szabó (1996) argued that teaching about orientation metaphors underlying phrasal verbs will result in a better acquisition of this difficult type of verbal structure. Bouton (1994) reported that formal instruction designed to develop pragmatic skills seemed to be highly effective when it was focused on formulaic implicatures that involve figurative conceptualization.

Approaches to teaching MC concretely have also been formulated across a broad spectrum of languages. The work of Littlemore (2009) and Lindstromberg (2009) is particularly relevant. These scholars show how language can be deconstructed into its conceptual parts and put back together pedagogically so that learners can grasp the conceptual system rationally even before engaging in communicative and other expressive tasks. One can, in fact, write conceptual grammars of the L2 in as straightforward a fashion as writing structural or communicative ones. As Holme (2010: 6) puts it, cognitive linguistics (under which $\mathrm{MC}$ and $\mathrm{CF}$ fall) provides relevant insights into devising appropriate pedagogy in SLT:

Cognitive Linguistics (CL) makes the functional assumption that form is motivated by meaning. CL also analyses form-meaning pairings as products of how cognition structures perception. CL thus helps teachers to fit language to the nature of the cognition that learns whilst devising modes of instruction that are better attuned to the nature of the language that has to be learnt... facets of a new approach are starting to emerge and that these can be broadly isolated according to four principles that comprise: embodied learning, conceptualization, the lexico-grammatical continuum, and usage. The principles interact one with another to consolidate the use of some older classroom methods and to point towards new ways of analyzing and presenting English lexis and grammar. They also set down key principles to direct research into classroom learning.

In effect, by teaching figurative concepts directly, one is indirectly teaching culture - a point made persuasively by Lantolf (1999). An important area of concern in this whole line of inquiry is, however, the distinction made in cognitive linguistics among metaphor, metonymy, and irony. There is no need to enter into this aspect here. However, the types of conceptual errors that appear in the L2 texts of beginning and intermediate learners are rarely infringements of these competencies - these seem to apply more to sophisticated kinds of text-constructions and thus will need to be taken into account in advanced courses of the L2 (Radden \& Kövecses, 1999). As the work in cognitive linguistics has been showing, conceptual metaphors continue to be at the heart of language and thus important for pedagogical purposes (Dirven and Vespoor, 1998, Ellis, 1998, 1999, Pütz, Niemeier, \& Dirven, 2001, Robinson \& Ellis, 2006, Hinkel, 2006, Sharifian \& Palmer, 2007, Pütz \& Aertselaer, 2008, Holme, 2009). There are problems and issues that need to be resolved, but then these are part of an ongoing research paradigm that puts figurative language at the core of the language faculty in both theory and pedagogical practice.

\section{References}

Achard, M., \& Niemeier, S. (Eds.) (2004). Cognitive linguistics, second language acquisition, and foreign language teaching. Berlin: Mouton de Gruyter.

Andreou, G., \& Galantomos, I. (2008). Designing a conceptual syllabus for teaching metaphors and idioms in a foreign language context. Porta Linguarum, 9, 69-77.

Andreou, G., \& Galantomos, I. (2009). Conceptual competence as a component of second language fluency. Journal of Psycholinguistic Research, 38, 587-591.

Andrews, E. (2014). Neuroscience and multilingualism. Cambridge: Cambridge University Press. 
Beréndi, M., Csábi, S., \& Kövecses, Z. (2008). Using conceptual metaphors and metonymies in vocabulary teaching. In F. Boers, \& S. Lindstromberg (Eds.), Cognitive linguistic approaches to teaching vocabulary and phraseology (pp. 6599). Berlin: Mouton de Gruyter.

Boers, F., \& Lindstromberg, S. (2009). Optimizing a lexical approach to instructed second language acquisition. Basingstoke: Palgrave Macmillan.

Boers, F. (1999). Learning vocabulary through metaphoric awareness. Études et Travaux, 3, 53- 65.

Boers, F. (2000a). Enhancing metaphoric awareness in specialized reading. English for Specific Purposes, 19, $137-147$.

Boers, F. (2000b). Metaphor awareness and vocabulary retention. Applied Linguistics, 21, 553-571.

Boers, F. (2001). Remembering figurative idioms by hypothesizing about their origin. Prospect, 16, 35-43.

Boers, F. (2004). Expanding learners' vocabulary through metaphor awareness: What expansion, what Learners, what vocabulary? In M. Achard, \& S. Niemeier (Eds.), Cognitive linguistics, second language acquisition, and foreign language teaching (pp. 211-232). Berlin: Mouton de Gruyter.

Boers, F. (2011). Cognitive semantic ways of teaching figurative phrases. Review of Cognitive Linguistics, 9, 227-261

Boers, F., \& Demecheleer, M. (2001). Measuring the impact of cross-cultural differences on learners' comprehension of imageable idioms. English Language Teaching Journal, 55, 255-262.

Boers, F., \& Lindstromberg, S. (2006). Cognitive linguistic applications in second or foreign language instruction: Rationale, proposals, and evaluation. In K. Gitte, M. Achard, R. Dirven, \& F. Ruiz de Mendoza (Eds.), Cognitive linguistics: Current applications, future orientations (pp. 305-355). Berlin: Mouton de Gruyter.

Boers, F., Demecheleer, M., \& Eyckmans, J. (2004). Cultural variation as a variable in comprehending and remembering figurative idioms. European Journal for English Studies, 8, 375-388.

Bortfeld, H. (2002). What native and non-native speakers' images for idioms tell us about figurative language. In R. R. Heredia, \& J. Altarriba (Eds.), Advances in psychology: Bilingual sentence processing (pp. 275-295). Amsterdam: John Benjamins.

Bouton, L. F. (1994). Can NNS skill in interpreting implicatures in American English be improved through explicit instruction? A pilot study. In L. F. Bouton, \& J. Kacher (Eds.), Pragmatics and language learning (pp. 88-110). Urbana-Champaign: University of Illinois Press.

Bowers, R. (1992). Memories, metaphors, maxims, and myths: Language learning and cultural awareness. English Language Teaching Journal, 46, 29-38.

Cameron, L. (2003). Metaphor in educational discourse. London: Continuum.

Cameron, L., \& Low, G. (Eds.) (1999). Researching and applying metaphor. Cambridge: Cambridge University Press.

Cameron, L., \& Stelma, J. (2005). Metaphor clusters in discourse: Methodological issues. Journal of Applied Linguistics, 1, 107-136.

Chapetón, C. M. (2010). Metaphor identification in EFL argumentative writing: A corpus-driven study. Folios, 32, $125-140$

Charteris-Black, J. (2002). Second language figurative proficiency: A comparative study of Malay and English. Applied Linguistics, 23, 104-133.

Connor, U. (1996). Contrastive rhetoric: Cross-cultural aspects of second-language writing. Cambridge: Cambridge University Press.

Cooper, T. C. (1999). Processing of idioms by L2 learners of English. TESOL Quarterly, 33, 233-262.

Danesi, M. (1986). The role of metaphor in second language pedagogy. Rassegna Italiana di Linguistica Applicata, 18, $1-10$.

Danesi, M. (1992). Metaphorical competence in second language acquisition and second language teaching: The neglected dimension. In J. E. Alatis (Ed.), Language communication and social meaning (pp. 489-500). Washington: Georgetown university round table on languages and linguistics.

Danesi, M. (1995). Learning and teaching languages: The role of conceptual fluency. International Journal of Applied Linguistics, 5, 3-20.

Danesi, M. (2000). Semiotics in language education. Berlin: Mouton de Gruyter.

Danesi, M. (2003). Second language teaching. A view from the right side of the brain. Dordrecht: Kluwer.

Danesi, M. (2008). Conceptual errors in second language learning. In S. De Knop, \& T. De Rycker (Eds.), Cognitive approaches to pedagogical grammar (pp. 231-256). Berlin: Mouton de Gruyter.

Danesi, M. (2013). On the metaphorical connectivity of cultural sign systems. Signs and Society, 1, 33-50

Danesi, M., \& Grieve, C. (2010). Conceptual error theory and the teaching of Italian. Italica, 87, 1-20.

Danesi, M., \& Rocci, A. (2009). Global linguistics: An introduction. Berlin: Mouton de Gruyter.

Deignan, A., Gabrys, D., \& Solska, A. (1997). Teaching English metaphors using cross-linguistic awareness-raising activities. English Language Teaching Journal, 51, 352-360.

Dirven, R., \& Verspoor, M. (1998) Cognitive exploration of language and linguistics. Amsterdam: John Benjamins 
Ellis, N. C. (1998). Emergentism, connectionism and language learning. Language Learning 48: 631-664.

Ellis, N. C. (1999). Cognitive approaches to SLA. Annual Review of Applied Linguistics, 19, 22-42.

Grabe, W., \& Kaplan, R. (1996). Theory and practice of writing. New York: Longman.

Grant, L., \& Bauer, L. (2004). Criteria for re-defining idioms: Are we barking up the wrong tree? Applied Linguistics, 25, 38-61.

Hashemian, M. (2013). Effects of focus-on-form(s) instruction on Iranian intermediate L2 learners' metaphorical competence development. Journal of Language Teaching Skills, 5, 1-17.

Hashemian, M., \& Nehzad, M. R. T. (2007). The development of conceptual fluency \& metaphorical competence in L2 learners. Linguistik Online, 30, 41-56.

Hinkel, E. (2006). Culture in second language teaching and learning. Cambridge: Cambridge University Press.

Holme, R. (2004). Mind, metaphor and language teaching. Basingstoke: Palgrave.

Holme, R. (2009). Cognitive linguistics and second language teaching. Basingstoke, England: Palgrave Macmillan.

Honeck, R. P., \& Hoffman, R. R. (Eds.) (1980). Cognition and figurative language. Hillsdale, N. J.: Lawrence Erlbaum Associates.

Irujo, S. (1986). A piece of cake: Learning and teaching idioms. ELT Journal, 40, 236-242.

Irujo, S. (1993). Steering clear. Avoidance in the production of idioms. International Review of Applied Linguistics, 31 , 205-219.

Johnson, J., \& Rosano, T. (1993). Relation of cognitive style to metaphor interpretation and second language proficiency. Applied Psycholinguistics, 14, 59-175.

Kaplan, R. D. (1966). Cultural thought patterns in inter-cultural education. Language Learning 16: 1-20.

Kaplan, R. D. (1978). Contrastive rhetoric: Some hypotheses. Review of Applied Linguistics, 39, 61-72.

Kecskes, I. (1999). Conceptual fluency and the use of situation-bound utterances in L2. Links \& Letters, 7, $145-161$.

Kecskes, I. (2000a). A cognitive-pragmatic approach to situation-bound utterances. Journal of Pragmatics, 32, 605-625.

Kecskes, I. (2000b). Conceptual fluency and the use of situation-bound utterances in L2. Links \& Letters, 7, $143-158$.

Kecskes, I., \& Papp, T. (2000a). Foreign language and mother tongue. Hillsdale, N. J.: Lawrence Erlbaum.

Kecskes, I., \& Papp, T. (2000b). Metaphorical competence in trilingual production. In Jason Cenoz and Ulrike Jessner, English in Europe: Acquisition of a Third Language, pp. 99-115. Clevedon: Multilingual Matters.

Kövecses, Z. (2001). A cognitive linguistic view of learning idioms in an FLT context. In Pütz, M., Niemeier, S. and Dirven, R. (Eds.), Applied Cognitive Linguistics. Language Pedagogy, vol. 2. Berlin \& New York: Mouton.

Kövecses, Z., \& Szabó, P. (1996). Idioms: A view from cognitive semantics. Applied Linguistics, 17, 326-355.

Lado, R. (1957). Linguistics across cultures: Applied linguistics for language teachers. Ann Arbor: University of Michigan Press.

Lado, R. (1964). Language teaching: A scientific approach. New York: McGraw-Hill.

Lakoff, G., \& Johnson, M. (1980). Metaphors we live by. Chicago: Chicago University Press.

Lakoff, G., \& Johnson, M. (1999). Philosophy in the flesh. New York: Basic Books.

Lantolf, J. P. (1999). Second culture acquisition. Cognitive considerations. In E. Hinkel (Ed.), Culture in second language teaching and learning (pp. 23-34). Cambridge: Cambridge University Press.

Lantolf, J. P., \& Thorne, S. L. (2006). Sociocultural theory and the genesis of second language development. Oxford: Oxford University Press.

Lazar, G. (1996). Using figurative language to expand students' vocabulary. English Language Teaching Journal, 50, 43-51.

Leki, I. (1991). Twenty-five years of contrastive rhetoric: Text analysis and writing pedagogies. TESOL Quarterly, 25, 123-143.

Li-yun, X. (2007). Effect of conceptual fluency on English oral communication. US-China Education Review, 4, 15-16.

Li, F. T. (2009). Metaphor, image, and image schemas in second language pedagogy: The acquisition of metaphorical expressions, idioms, and proverbs by Chinese learners of English. Berlin: Lambert Academic Publishing.

Lindstromberg, S. (2010). English prepositions explained. 2nd ed. Amsterdam: John Benjamins.

Lindstromberg, S. (1991). Metaphor and ESP. A ghost in the machine? English for Specific Purposes, 10, $207-225$.

Lindstromberg, S. (1996). Prepositions: Meaning and method. English Language Teaching Journal, 50, 225-236.

Lindstromberg, S. (1998). English prepositions explained. Amsterdam: John Benjamins.

Littlemore, J. (2001a). Metaphoric competence: A possible language learning strength of students with a holistic cognitive style? Tesol Quarterly, 34, 459-491.

Littlemore, J. (2001b). Metaphoric intelligence and foreign language learning. Humanising Language Teaching, 3.2. http:/ www .hltmag.co.uk/ mar01 /martl. htm. 
Littlemore, J. (2009). Applying cognitive linguistics to second language learning and teaching. Basingstoke: Palgrave Macmillan.

Littlemore, J., \& Low, G. D. (2006a). Metaphoric competence, second language learning, and communicative language ability. Applied Linguistics, 27, 268-294.

Littlemore, J., \& Low, G. D. (2006b). Figurative thinking and foreign language learning. New York: Palgrave Macmillan.

Low, G. D. (1988). On teaching metaphor. Applied Linguistics, 9, 125-147.

MacLennan, C. H. G. (1994). Metaphors and prototypes in the learning and teaching of Grammar and Vocabulary. International Review of Applied Linguistics, 32, 97-110.

Mahmoodzadeh, M. (2014). Reflections on the development of contrastive domain of second language education: An overview. International Letters of Social and Humanistic Sciences, 6, 1-8.

Matsuda, P. K. (1997). Contrastive rhetoric in context: A dynamic model of L2 writing. Journal of Second Language Writing, 6, 45-60.

Nacey, S. (2013). Metaphors in learner English. Amsterdam: John Benjamins.

Norafkan, M. (2013). Learnability of cultural models through authentic materials: Focus on metaphorical competence and conceptual fluency. Doctoral Dissertation, Simon Fraser University.

Ortony, A. (Ed.) (1979). Metaphor and thought. Cambridge: Cambridge University Press.

Palmer, G. B. (1996). Toward a theory of cultural linguistics. Austin: University of Texas Press.

Philip, G. (2010). Drugs, traffic, and many other dirty interests: Metaphor and the language learner. In L. Graham, A. Deignan, L. Cameron, \& T. Zazie (Eds.) Researching and Applying Metaphor in the Real World (pp. 63-80). Amsterdam: John Benjamins.

Piper, D. (1985). Contrastive rhetoric and reading in second language: Theoretical perspectives on classroom practice. Canadian Modern Language Review, 42, 34-43.

Pollio, H., Barlow, J., Fine, H., \& Pollio, M. (1977). The poetics of growth: Figurative language in psychology, psychotherapy, and education. Hillsdale, N. J.: Lawrence Erlbaum Associates.

Pütz, M., \& Aertselaer, J. N. (Eds.) (2008). Developing contrastive pragmatics. Berlin: Mouton de Gruyter.

Pütz, M., Niemeier, S., \& Dirven, R. (Eds.) (2001). Applied cognitive linguistics: Theory and language acquisition. Berlin: Mouton de Gruyter.

Radden, G., \& Dirven, R. (2007). Cognitive English grammar. Amsterdam: John Benjamins.

Radden, G., \& Kövecses, Z. (1999). Towards a theory of metonymy. In G. Radden, \& K.U. Panther (Eds.), Metonymy in cognition and language (pp. 17-60). Amsterdam: John Benjamins.

Robinson, P., \& Ellis, N. (Eds.) (2006). Handbook of cognitive linguistics and second language acquisition. Hillsdale, N. J.: Lawrence Erlbaum

Russo, G. A. (1997). A conceptual fluency framework for the teaching of Italian as a second language. Unpublished doctoral dissertation, University of Toronto.

Sharifian, F., \& Palmer, G. B. (Eds.) (2007). Applied cultural linguistics: Implications for second language learning and intercultural communication. Amsterdam: John Benjamins.

Shirazi, M. G., \& Talebinezhad, M. R. (2013). Developing intermediate EFL learners' metaphorical competence through exposure. Theory and Practice in Language Studies, 3, 135-141.

Skoufaki, S. (2008). Conceptual metaphoric meaning clues in two idiom presentation methods. In F. Boers, \& S. Lindstromberg (Eds.), Cognitive linguistic approaches to teaching vocabulary and phraseology (pp. 101-132). Berlin: Mouton de Gruyter.

Stefanowitsch, A. (2006). Corpus-Based approaches to metaphor and metonymy. In A. Stefanowitsch \& S. Gries (Eds.), Corpus-Based Approaches to Metaphor and Metonymy (pp. 1-16). Berlin/New York: Mouton de Gruyter.

Tyler, A. (2008). Cognitive linguistics and second language instruction. In P. Robinson, \& N. C. Ellis (Eds.), Handbook of cognitive linguistics and second language acquisition (pp. 456-488). London: Routledge.

Tyler, A., \& Evans, V. (2004). Applying cognitive linguistics to pedagogical grammar: The case of over. In M. Achard, \& S. Niemeier (Eds.), Cognitive linguistics, second language acquisition, and foreign language teaching (pp. 257-280). Berlin: Mouton de Gruyter.

Valeva, G. (1996). On the notion of conceptual fluency in a second language. In A. Pavlenko, \& R. S. Salaberry (Eds.), Cornell working papers in linguistics: Papers in second language acquisition and bilingualism (pp. 22-38). Ithaca: Cornell University.

Van Ek, J. A. (1975). The threshold level in a European unit/credit system for modern language teaching by adults. Strasbourg: Council of Europe.

Velasco Sacristán, M. (2005). Metaphor and ESP: Metaphor as a useful device for teaching L2 business English learners. Ibérica, 10, 115-131.

Weinreich, U. (1953). Languages in contact: Findings and problems. The Hague: Mouton.

Wilkins, D. A. (1976). Notional syllabuses. Oxford: Oxford University Press. 